\title{
Quantitative Chemical Analysis of Fluorine in the Slags Produced in Stainless Argon-0xygen Decarburization Process by X-ray Fluorescence Spectrometry
}

\author{
Sung-Mo JUNG \\ Graduate Institute of Ferrous Technology, Pohang University of Science and Technology, San 31, Hyoja-dong, Nam-gu, Pohang \\ 790-784, Korea.
}

(Received on April 11, 2007; accepted on June 5, 2007)

\begin{abstract}
A quantitative analysis method of fluorine in the slags produced in the stainless argon-oxygen decarburization (STS AOD) process by X-ray spectrometry was proposed employing fusion pretreatment technique. The research concerned the separate quantification of calcium fluoride and calcium oxide contained in stainless AOD slags. X-ray diffraction measurement was performed to identify the stable phase of fluorine compound, which is primarily present in the slags. Homogeneous glass discs were prepared under the following conditions: lithium borate mix as flux with sample dilution (1:15), with the addition of one tablet of ammonium iodide as releasing agent at $1323 \mathrm{~K}$ for $20 \mathrm{~min}$. XRD patterns and semi-quantitative results for the STS AOD slags provided synthetic standards based on the approximate compositional range of STS AOD slags by combining highly pure compounds and oxides. These standards were employed to establish the XRF calibration curves for $\mathrm{F}, \mathrm{Ca}_{\mathrm{t}} \mathrm{O}, \mathrm{SiO}_{2}, \mathrm{MgO}, \mathrm{Al}_{2} \mathrm{O}_{3}$ and $\mathrm{Cr}_{2} \mathrm{O}_{3}$. The calibration curves were used in the quantitative analysis of a synthetic standard and an pure calcium fluoride with satisfactory precision and accuracy, considering the matrix effects and line overlap corrections. The suggested method might be a useful solution to the problem with the quantitative analyses of calcium fluoride in stainless AOD slags by XRF spectrometry.
\end{abstract}

KEY WORDS: stainless steelmaking slags; fluorine; calcium oxide; calcium fluoride; fused glass disc; calibration standards; XRF spectrometry; quantification.

\section{Introduction}

Fluorine in metallurgical slags and fluxes plays an essential role in controlling physicochemical properties of oxide mixtures. ${ }^{1,2)}$ Especially, calcium fluoride $\left(\mathrm{CaF}_{2}\right)$ has been widely used for a variety of applications in the glass- and steel-manufacturing industry. One advantage of fluorine addition to steelmaking slags is an increase in the range of the liquid phase field, which leads to high productivity and effective quality control. ${ }^{3)}$ It was also reported that $\mathrm{CaF}_{2}$ increases the activity of $\mathrm{Fe}_{\mathrm{t}} \mathrm{O}$ and phosphate capacity of slags according to the research on the $\mathrm{CaO}-\mathrm{CaF}_{2}-\mathrm{Fe}_{\mathrm{t}} \mathrm{O}$ slags for the recycling of basic oxygen furnace (BOF) slags. ${ }^{4}$ That is, it was established that $\mathrm{CaF}_{2}$ is one of the most effective additives for decreasing the melting point of slags and that it helps to improve slag refining capacities. Due to this versatility, appreciable amount of calcium fluoride has been used as one of the constituents in ladle, tundish, mold slags, and stainless argon-oxygen decarburization (STS AOD) slags. In particular, it is difficult to interpret the real processes utilizing fluorine-containing fluxes based on quantitative fluorine data since the standard analysis methods of fluorine contained in stainless AOD slags are not available. Although several wet chemical analysis methods of fluorine in slags were proposed, they could not provide the reproducible results. ${ }^{5,6)}$

Over a number of years, X-ray fluorescence spectrometry (XRF) has been widely used as a routine and rapid instrumental analysis technique for quantifying minerals, slags, oxides, etc. A variety of applications has emerged for this established XRF technique. ${ }^{7)}$ The primary objective of the present research is to establish a simple and reliable XRF method of analyzing the components in the fluorine-containing slags produced in the steelmaking AOD process by preparing the standard reference materials for constructing the calibration curves.

\section{Experimental}

\subsection{X-ray Fluorescence Spectrometer}

Bruker-AXS S4 Pioneer wavelength dispersive X-ray fluorescence spectrometer (WD-XRF) was employed in this research. The XRF was equipped with an end window Rhtarget X-ray tube of the maximum output of $4 \mathrm{~kW}$ and eight diffracting crystals of various d-spacings. The measuring conditions and goniometer settings were programmed by the Bruker-AXS software "SpectraPlus" and summarized in Table 1. This application software was employed to calculate theoretical "variable alpha coefficients." Alpha coefficients correct the absorption or enhancement of secondary 
Table 1. Summary of the spectrometer settings used in the present study.

\begin{tabular}{|c|c|c|c|c|c|c|}
\hline & $\mathbf{F}$ & $\mathrm{Ca}_{t} \mathrm{O}$ & $\mathrm{SiO}_{2}$ & MgO & $\mathrm{Al}_{2} \mathrm{O}_{3}$ & $\mathrm{Cr}_{2} \mathrm{O}_{3}$ \\
\hline Spectral line & F KA1-HS-Min & Ca KA1-Maj & Si KA1-Maj & Mg KA1-HS-Min & Al KA1-HS-Min & Cr KA1-HS-Min \\
\hline (Energy) & $(0.68 \mathrm{keV})$ & $(3.7 \mathrm{keV})$ & $(1.7 \mathrm{keV})$ & $(1.3 \mathrm{keV})$ & $(1.5 \mathrm{keV})$ & $(5.4 \mathrm{keV})$ \\
\hline Tube Voltage(kV) & 27 & 50 & 27 & 27 & 27 & 60 \\
\hline Tube Current(mA) & 114 & 10 & 20 & 114 & 114 & 51 \\
\hline Crystal & OVO-55 & LiF200 & PET & OVO-55 & PET & LiF200 \\
\hline \multicolumn{7}{|l|}{ Collimator } \\
\hline & $0.46^{\circ}$ & $0.23^{\circ}$ & $0.23^{\circ}$ & $0.46^{\circ}$ & $0.46^{\circ}$ & $0.46^{\circ}$ \\
\hline \multicolumn{7}{|l|}{ Aperture } \\
\hline & Proportional & Proportional & Proportional & Proportional & Proportional & Scintillation \\
\hline \multicolumn{7}{|l|}{ Detector } \\
\hline & counter & counter & counter & counter & counter & counter \\
\hline Adjusted Peak(20) & $38.574^{\circ}$ & $113.109^{\circ}$ & $109.016^{\circ}$ & $20.547^{\circ}$ & $144.678^{\circ}$ & $69.374^{\circ}$ \\
\hline Wavelength( $(\AA)$ & 18.313 & 3.3584 & 7.1254 & 9.893 & 8.3393 & 2.2897 \\
\hline Background $1(2 \theta)$ & 40.851 & 114.404 & 110.461 & 18.975 & 147.325 & 66.767 \\
\hline (Weight) & & & & $(0.5739)$ & & $(0.4683)$ \\
\hline Background $2(2 \theta)$ & None & None & None & 22.665 & None & 71.665 \\
\hline (Weight) & & & & $(0.4261)$ & & $(0.5317)$ \\
\hline
\end{tabular}

Table 2. Compositions of fluorine-containing reference materials available in markets.

\begin{tabular}{|c|c|c|c|c|c|c|c|c|c|c|}
\hline \multirow{2}{*}{$\begin{array}{l}\text { Reference } \\
\text { Materials }\end{array}$} & \multicolumn{10}{|c|}{ Composition (mass\%) } \\
\hline & $\mathbf{F}$ & $\mathrm{CaO}$ & $\mathrm{SiO}_{2}$ & MgO & $\mathbf{A l}_{2} \mathbf{O}_{3}$ & MnO & $\mathrm{FeO}$ & $\mathrm{Cr}_{2} \mathrm{O}_{3}$ & $\mathbf{s}$ & Sum \\
\hline S8 Slag ${ }^{8)}$ & 2.0 & 36.5 & 39.9 & 5.7 & 6.8 & 4.7 & 0.8 & 3.7 & 0.13 & 100.23 \\
\hline S9 ESR Slag9) & 17.3 & 29.1 & 1.4 & 2.2 & 31.5 & - & 0.04 & - & - & 81.54 \\
\hline
\end{tabular}

radiation due to inter-element or matrix effects. The XRF was used to measure synthetic standards in scan mode, and the optimal positions of highest signal intensities of peak and background were determined by overlapping the data files measured in scan mode. Subsequent XRF calibration and measurement were carried out in fixed mode.

\subsection{Availability of Standard Reference Materials Con- taining Fluorine for XRF Calibration}

$\mathrm{X}$-ray fluorescence spectrometry is a comparative technique, which means that the quantification of elements is based on predetermined calibration curves obtained from calibration standards. Thus, analyzing unknown STS AOD slags containing fluorine strongly depends on the availability of certified reference materials. In this investigation, only two reference materials were available. The certified concentrations of the two reference materials are listed in Table 2. ${ }^{8,9)}$

\subsection{Preparation Procedure of Synthetic Standards and Prior Treatment of Samples}

Since sufficient standard reference materials for XRF analysis of STS AOD slags are not available, 13 synthetic standards were prepared by mixing special-grade chemicals of higher than $99.99 \%$ purity to be used for XRF calibration. Once the target composition of a synthetic standard was determined, the accurate amount of each chemical was weighed and poured into a $250-\mathrm{mL}$ of polyethylene bottle containing alumina balls of $10 \mathrm{~mm}$ diameter. The powder in the bottle was mixed and ground for more than $24 \mathrm{~h}$ by employing a ball mill technique so that the particle size was decreased to approximately less than $10 \mu \mathrm{m}$, and afterwards the homogeneous powder was dried in a desiccator.

For the XRF measurement of samples in the form of pressed pellets, boric acid powder was first lightly packed to a $40 \mathrm{~mm}$ aluminum cup inside a $42 \mathrm{~mm}$ ID cylindrical die. Then an accurately weighed portion of each sample was added in sufficient amount to cover the top of the boric acid powder. Finally a plunger was inserted into the die and hydraulic pressure was applied in a briquetting press (Her- 
Table 3. Accuracy and precision tests of the reference materials containing 2.0 and 17.3 mass $\%$ fluorine. (Units: mass $\%$ )

\begin{tabular}{|c|c|c|c|c|}
\hline \multirow{2}{*}{ Tests } & \multicolumn{2}{|c|}{ S8 Slag $(F=2.0 \text { mass } \%)^{8)}$} & \multicolumn{2}{|c|}{ S9 ESR Slag $(F=17.3 \text { mass } \%)^{9)}$} \\
\hline & $\mathrm{KMnO}_{4}$ titration $^{5)}$ & F ion electrode $e^{6)}$ & $\mathrm{KMnO}_{4}$ titration $^{5)}$ & $F$ ion electrode ${ }^{6)}$ \\
\hline Test1 & 0.90 & 1.90 & 17.23 & 8.47 \\
\hline Test2 & 0.93 & 1.92 & 18.76 & 9.04 \\
\hline Test3 & 0.87 & 1.81 & 17.74 & 8.70 \\
\hline Test4 & 1.07 & 1.86 & 15.37 & 8.76 \\
\hline Test5 & 0.88 & 2.15 & 17.74 & 8.20 \\
\hline Average & 0.93 & 1.93 & 17.37 & 8.63 \\
\hline $\begin{array}{l}\text { Standard } \\
\text { deviation }\end{array}$ & 0.073 & 0.117 & 1.116 & 0.283 \\
\hline $\begin{array}{c}\text { Precision RSD } \\
(\%)\end{array}$ & 7.84 & 6.08 & 6.42 & 3.28 \\
\hline
\end{tabular}

zog, maximum pressure 40 ton). Only one face of sample material in the resulting sample disc encased in an aluminum dish was exposed for analysis. Briquettes formed in this manner remained intact after repeated analyses, provided they were stored in a dessicator.

The borate fusion technique was employed in order to eliminate particle size and mineralogical effects. About $7.5 \mathrm{~g}$ of borate flux (Lithium borate mix, $66 \% \mathrm{Li}_{2} \mathrm{~B}_{4} \mathrm{O}_{7}+$ $34 \% \mathrm{Li}_{2} \mathrm{~B}_{3} \mathrm{O}_{4}$ or Lithium tetraborate, $\mathrm{Li}_{2} \mathrm{~B}_{4} \mathrm{O}_{7}$ ) was first weighed in a platinum crucible $(5 \% \mathrm{Au} / \mathrm{Pt})$ and then $0.5 \mathrm{~g}$ of a sample was put in the crucible (dilution factor $=1: 15$ ). Then, one ammonium iodide tablet of $21.4 \mathrm{mg}$ was added to serve as a releasing agent. Essentially, the fusion procedure consists of heating a mixture of sample and flux at high temperatures $(1323 \mathrm{~K}$ for Lithium borate mix and $1373 \mathrm{~K}$ for Lithium tetraborate) using a fusion machine (AFT Phoenix 6000C). ${ }^{10}$ ) The overall composition and cooling conditions must be such that the end product after cooling is a homogenous glass disc.

\section{Results and Discussion}

\subsection{Fluorine Analysis Using Previously Proposed Methods}

Several different methods of analyzing fluorine in oxide mixtures have been reported to date as earlier mentioned. ${ }^{5,6)}$ In the present study, accuracy and precision tests for two methods were carried out using two reference materials containing fluorine (S8 Slag and S9 ESR Slag) as shown in Table 3. From the results in Table 3, the analyzed fluorine content by the $\mathrm{F}$ ion electrode method is closer to that of $\mathrm{S} 8$ Slag than the value obtained by the $\mathrm{KMnO}_{4}$ titration technique using acetic acid. However, according to the repeatability data for S8 Slag, none of the methods show satisfactory precision because all the precision RSD (precision $\operatorname{RSD}(\%)=$ standard deviation/average $\times 100)$ values indicating repeatability exceeded $5 \%$. On the other hand, in the case of S9 ESR Slag, the analysis result by $\mathrm{KMnO}_{4}$ titration is nearly approximate to the fluorine concentration in the certified value of S9 ESR Slag. And the precision RSD values of repeatability tests were not believed to be acceptable except for the value obtained by the F ion electrode analysis

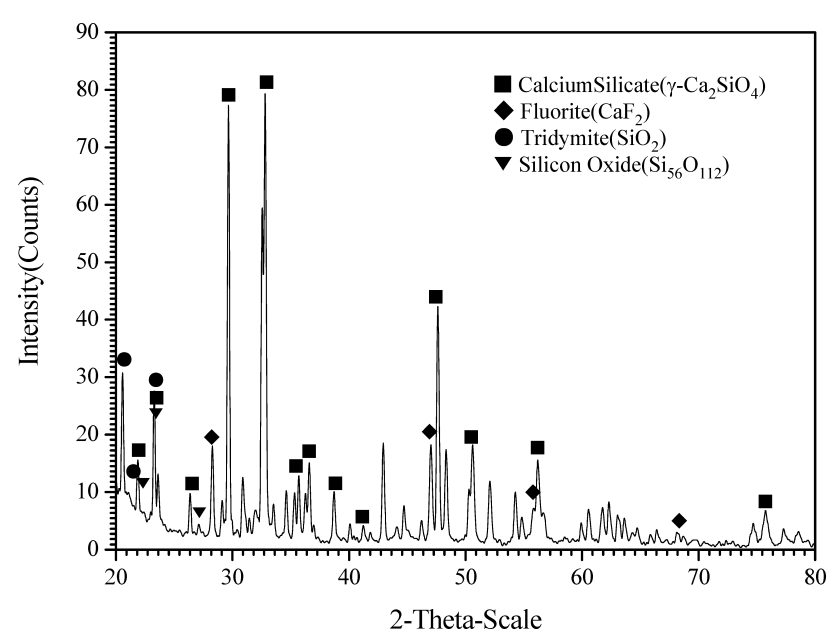

Fig. 1. X-ray diffraction pattern for a slag produced in POSCO stainless AOD process.

for S9 ESR Slag. It would seem that the titration method is more suitable for higher $\mathrm{F}$ values and the ion selective electrode method is more appropriate for lower F values, therefore as indicated in Table 3 , in case the two reference materials were analyzed using the conventional analysis methods of fluorine, neither can be considered suitable for a wide range of $\mathrm{F}$ concentrations.

\subsection{X-ray Diffraction Pattern and Semi-quantitative XRF Analysis of an STS AOD Slag}

It has been reported that fluorine compounds in oxides and metallurgical slags usually exist in the form of fluorides such as $\mathrm{CaF}_{2}, \mathrm{NaF}, \mathrm{BaF}_{2}$, etc. depending on the coexisting compounds and temperature. ${ }^{1,2,11,12)}$ In fact, X-ray fluorescence spectrometry analyzes the concentrations of cations or anions (e.g. $\mathrm{F}, \mathrm{Cl}, \mathrm{N}$, etc.) and then converts them to those of compounds which are assumed to be most likely to exist in a sample. Therefore, in order to quantify a fluorine compound and other constituents in a factory sample, the existing form of fluorine should be identified in advance. According to the X-ray diffraction pattern of the factory slag sample (STS AOD slag) shown in Fig. 1, the primary component of the slag sample, $\mathrm{CaO}$, is present in the form of $\gamma-2 \mathrm{CaO} \cdot \mathrm{SiO}_{2}$, which is also one of the primary phases of general steelmaking slags. And it was indicated that, es- 
Table 4. A semi-quantitative XRF analysis of an unknown STS AOD slag.

\begin{tabular}{cccccccccc}
\hline Constituents & $\mathrm{F}\left(\mathrm{CaF}_{2}\right)$ & $\mathrm{Ca}_{\mathbf{t}} \mathrm{O}(\mathrm{CaO})$ & $\mathrm{SiO}_{2}$ & $\mathrm{MgO}$ & $\mathrm{Al}_{2} \mathrm{O}_{3}$ & $\mathrm{Cr}_{2} \mathrm{O}_{3}$ & $\mathrm{TiO}_{2}$ & $\mathrm{FeO}$ & \multirow{2}{*}{$\mathrm{Sum}$} \\
\hline mass\% & $6.00(12.3)$ & $64.4(55.5)$ & 25.7 & 5.95 & 1.05 & 0.489 & 0.289 & 0.150 & $104(101.4)$ \\
\hline
\end{tabular}

pecially, fluorine exists only in the form of fluorite $\left(\mathrm{CaF}_{2}\right)$. Thus, in case a semi-quantitative XRF analysis of the STS AOD slag is performed as shown in Table 4, it is believed that it is necessary to analyze the slag concentrations in terms of fluorine and total calcium oxide $\left(\mathrm{Ca}_{\mathrm{t}} \mathrm{O}\right)$ and to convert those to the contents of $\mathrm{CaF}_{2}$ and $\mathrm{CaO}$, respectively, using Eqs. (1) to (5).

$$
\begin{aligned}
& (\operatorname{mass} \% \mathrm{TCa})=\left(\operatorname{mass} \% \mathrm{Ca}_{\mathrm{t}} \mathrm{O}\right) \times \frac{A W_{\mathrm{Ca}}}{M W_{\mathrm{CaO}}} \\
& \left(\operatorname{mass} \% \mathrm{CaF}_{2}\right)=(\operatorname{mass} \% \mathrm{~F}) \times \frac{1}{2} \times \frac{M W_{\mathrm{CaF}_{2}}}{A W_{\mathrm{F}}} \\
& (\operatorname{mass} \% \mathrm{Ca})_{\mathrm{CaF}_{2}}=\left(\operatorname{mass} \% \mathrm{CaF}_{2}\right) \times \frac{A W_{\mathrm{Ca}}}{M W_{\mathrm{CaF}_{2}}} \\
& (\operatorname{mass} \% \mathrm{Ca})_{\mathrm{CaO}}=(\operatorname{mass} \% \mathrm{TCa})-(\operatorname{mass} \% \mathrm{Ca})_{\mathrm{CaF}_{2}} \\
& (\operatorname{mass} \% \mathrm{CaO})=(\operatorname{mass} \% \mathrm{Ca})_{\mathrm{CaO}} \times \frac{M W_{\mathrm{CaO}}}{A W_{\mathrm{Ca}}}
\end{aligned}
$$

where (mass $\% i), A W_{j}$ and $M W_{\mathrm{j}}$ represent the mass percent of component $i$, atomic and molecular weight of component $j$, respectively. On the other hand, according to X-ray diffraction patterns of S8 Slag and S9 ESR Slag reference materials in Fig. 2, a specific peak indicating fluorine compound phase was not observed for S8 Slag, but some peaks representing a mixture of $\mathrm{CaF}_{2}$ and calcium aluminum oxide were identified for S9 ESR Slag. Therefore, it is more straightforward to deal with STS AOD slags since fluorine only exists in the form of $\mathrm{CaF}_{2}$, which makes it possible to convert the contents of fluorine and total calcium oxide into those of $\mathrm{CaF}_{2}$ and $\mathrm{CaO}$.

\subsection{Preparation of Synthetic Standards by Physical Mixing of Constituents Comprising STS AOD Slags}

The previous discussion has shown that any conventional method of analyzing fluorine could not provide reliable analysis results. Furthermore, any certified reference material containing fluorine is not available. As an alternative, attempt has been made to prepare a synthetic powder by mixing highly pure chemicals so that their calculated compositions were similar to those of STS AOD slags. The synthetic material was then pre-treated into a glass disc by means of the borate fusion technique and shaped into a pressed pellet, respectively, for the semi-quantitative XRF measurement. As shown in Table 5, the analysis result by the borate fusion technique was more approximate to the initially calculated concentration compared with that by a pellet sample. It is believed that the borate fusion technique is more effective in eliminating mineralogical and particle size effects. ${ }^{13)}$ Therefore, the borate fusion technique was employed in pre-treating synthetic standards containing flu-
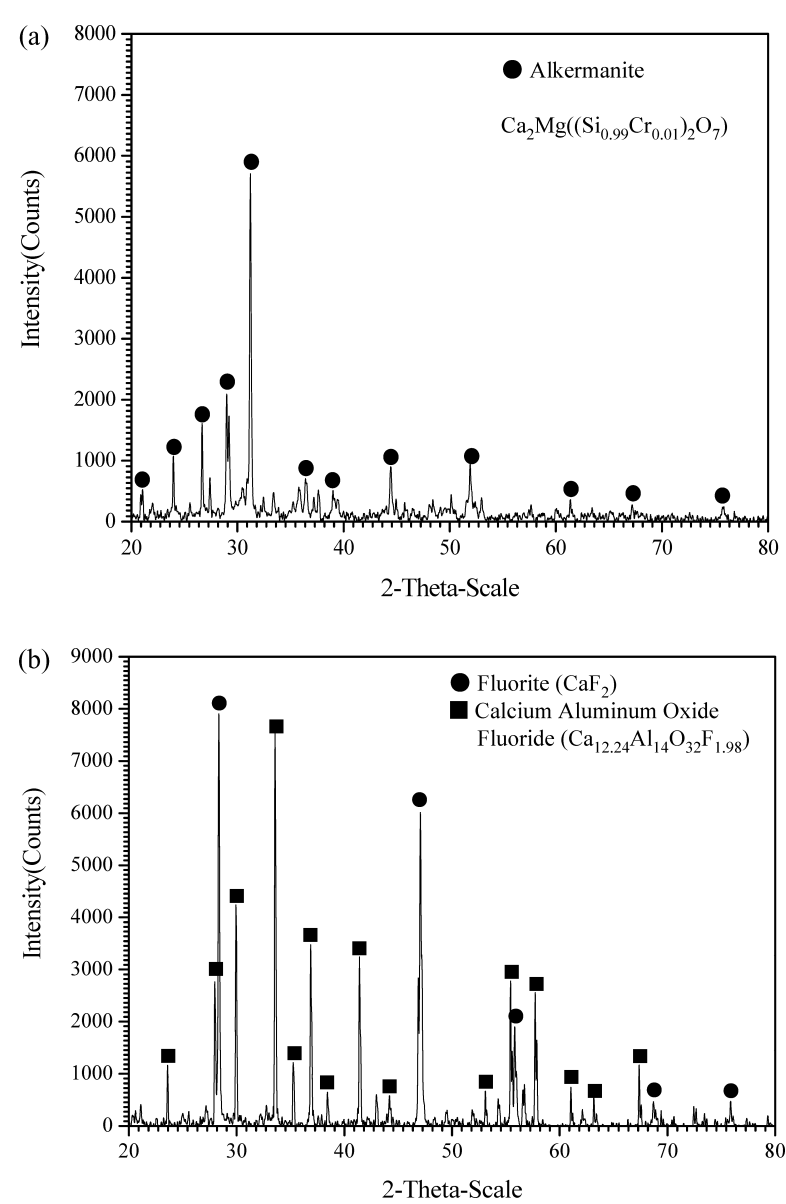

Fig. 2. X-ray diffraction patterns for the reference materials of S8 Slag ${ }^{8)}$ (a) and S9 ESR Slag ${ }^{9)}$ (b).

orine for XRF quantitative analyses of STS AOD slags.

\subsection{Effect of Borate Fusion Sample Preparation on the Change of Sample Weight}

In general, lithium tetraborate $\left(\mathrm{Li}_{2} \mathrm{~B}_{4} \mathrm{O}_{7}\right)$ and lithium borate mix $\left(66 \% \mathrm{Li}_{2} \mathrm{~B}_{4} \mathrm{O}_{7}+34 \% \mathrm{Li}_{2} \mathrm{~B}_{3} \mathrm{O}_{4}\right)$ are glass-forming fluxes used for borate fusion techniques. ${ }^{10)}$ The melting points of lithium borate mix and lithium tetraborate are 1148 and $1193 \mathrm{~K}$, respectively. In real fusion processes, 1323 and $1373 \mathrm{~K}$ are recommended for lithium borate mix and Lithium tetraborate flux, respectively, taking into account for the melting points and mutual chemical intimacy between sample and flux. ${ }^{7)}$ According to the previous study, elements such as $\mathrm{Na}, \mathrm{K}, \mathrm{S}, \mathrm{Cl}$, etc. easily vaporize when the borate fusion process is carried out at above $1323 \mathrm{~K}^{14)}$ Loubser et al. ${ }^{15)}$ also pointed out that the weight loss of flux could influence analyte quantification by XRF. Therefore, it is necessary to examine the possibility of fluorine vaporization in STS AOD slag and other types of samples in the present study. In particular, an optimal borate fusion technique for XRF analysis of STS AOD Slags should be developed considering the weight change of samples and fluxes resulted from specimen preparation. 
Table 5. Comparison of semi-quantitative analysis results of a synthetic standard in terms of sample preparation.

\begin{tabular}{|c|c|c|c|c|c|c|c|}
\hline \multirow{2}{*}{ Sample Name } & \multicolumn{7}{|c|}{ Composition (mass\%) } \\
\hline & $\mathrm{F}\left(\mathrm{CaF}_{2}\right)$ & $\mathrm{Ca}_{\mathrm{t}} \mathrm{O}(\mathrm{CaO})$ & $\mathrm{SiO}_{2}$ & MgO & $\mathrm{Al}_{2} \mathbf{O}_{3}$ & $\mathrm{Cr}_{2} \mathrm{O}_{3}$ & Sum \\
\hline $\begin{array}{l}\text { Synthetic standard } \\
\text { (Calculated conc.) }\end{array}$ & $5.84(12.0)$ & $63.6(55.0)$ & 25.00 & 5.00 & 1.00 & 1.00 & $101.5(99.0)$ \\
\hline $\begin{array}{l}\text { Semi-quantitative XRF } \\
\text { analysis (Glass bead by } \\
\text { borate fusion) }\end{array}$ & $6.81(14.0)$ & $64.9(54.8)$ & 24.20 & 4.95 & 1.00 & 0.90 & $102.7(99.8)$ \\
\hline $\begin{array}{l}\text { Semi-quantitative XRF } \\
\text { analysis (Pressed pellet) }\end{array}$ & $11.4(23.4)$ & $68.5(51.7)$ & 34.6 & 6.63 & 0.381 & 1.07 & $122.6(116.7)$ \\
\hline
\end{tabular}

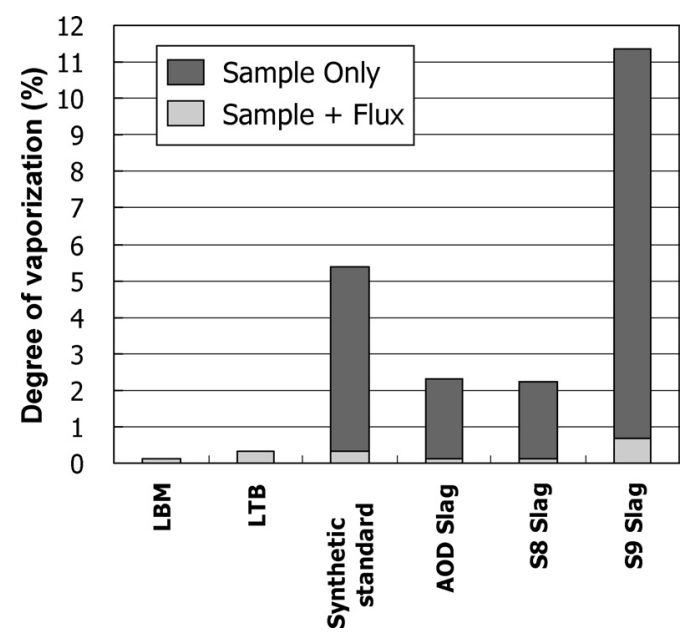

Fig. 3. Degrees of vaporization influenced by the kind of samples and borate fusion fluxes. (LBM: lithium borate mix, LTB: lithium tetraborate).

The degree of vaporization was considered in terms of the total weight decrease with respect to the initial weight of samples and used fluxes, which were plotted in Fig. 3. It was indicated that the degrees of vaporization are less than $1 \%$ for the samples and fluxes tested.

$$
\begin{aligned}
& \text { Degree of vaporization }(\%)_{\text {Sampe }+ \text { Flux }} \\
& =\frac{-\Delta W_{\text {Sample+Flux }}}{\left(W_{\text {Sample }+ \text { Flux }}\right)_{\mathrm{i}}} \times 100
\end{aligned}
$$

Degree of vaporization $(\%)_{\text {Sample Only }}$

$$
=\frac{\Delta W_{\text {Flux }}-\Delta W_{\text {Sample }+ \text { Flux }}}{W_{\text {Sample }}} \times 100
$$

In order to compare the degrees of vaporization for the samples only, the weight change calculated using Eq. (7) was taken into consideration. It was shown that the weight change of lithium borate mix is smaller than that of lithium tetraborate. When comparing the vaporization results of STS AOD slag in Fig. 3, the degree of vaporization of STS AOD slag is $0.14 \%$ and almost the same as that of lithium borate mix. This means that lithium borate mix might be a more nonvolatile flux used for the borate fusion process of STS AOD slags compared with lithium tetraborate flux. In Fig. 3, the weight decrease of the synthetic standard was estimated to be about $5 \%$, which could be accepted within the uncertainty of synthetic standard preparation. When comparing the results of the two reference samples (S8 Slag and S9 ESR Slag), the weight loss of S9 ESR Slag is remarkably greater than that of S8 Slag. Therefore, the weight losses of samples resulted from a borate fusion process could be variable depending on the coexisting elements or on the kind of phases the elements of interest exist in. ${ }^{14)}$ However, comparing the degrees of vaporization for the synthetic standard and STS AOD slag, it is believed that the relative degrees of vaporization for sample and flux to that for sample only show similar tendency, which can be interpreted that both samples can be pretreated employing borate fusion technique for constructing calibration curves and measuring unknown STS AOD slags.

\subsection{Preparing Synthetic Standards for XRF Calibra- tion}

Since the analysis method for fluorine in STS AOD slags was not repeatable, several synthetic standards containing $\mathrm{CaF}_{2}$ were prepared by mixing highly pure chemicals so that they cover the compositional range of STS AOD slags as shown in Table 6. Table 6 shows the detailed target compositions of 13 synthetic standards prepared in the laboratory, referring to the approximate compositional range of STS AOD slags produced in POSCO. The compositions of 13 synthetic standards in Table 6 cannot be directly entered into the XRF calibration software because two different phases of calcium $\left(\mathrm{CaF}_{2}\right.$ and $\left.\mathrm{CaO}\right)$ are present. Therefore, the compositions in Table 6 were converted to those of fluorine $(\mathrm{F})$ and total calcium oxide $\left(\mathrm{Ca}_{\mathrm{t}} \mathrm{O}\right)$ using Eqs. (1) to (5) in the reverse order to that in Table 4.

This procedure is essential for XRF calibration because it is necessary to establish XRF calibration curves covering wide range of compositions and to simultaneously meet the requirement of variable alpha coefficient method for matrix corrections, where the sum of all the phase compositions are more than 90 mass $\%$ for the standard materials used. ${ }^{16)}$ 
Table 6. Gravimetrically calculated compositions of synthetic standards for XRF calibration.

\begin{tabular}{|c|c|c|c|c|c|c|c|}
\hline \multirow{2}{*}{$\begin{array}{l}\text { Synthetic } \\
\text { standards }\end{array}$} & \multicolumn{7}{|c|}{ Compositions (mass\%) } \\
\hline & $\mathrm{F}\left(\mathrm{CaF}_{2}: 2 \sim 19\right)$ & $\mathrm{Ca}_{\mathrm{t}} \mathrm{O}(\mathrm{CaO}: 50 \sim 60)$ & $\begin{array}{c}\mathrm{SiO}_{2} \\
(\mathbf{2 0} \sim \mathbf{3 0})\end{array}$ & $\begin{array}{c}\mathrm{MgO} \\
(2.0 \sim 9.0)\end{array}$ & $\begin{array}{c}\mathrm{Al}_{2} \mathrm{O}_{3} \\
(\mathbf{0 . 5} \sim \mathbf{2 . 0})\end{array}$ & $\begin{array}{c}\mathrm{Cr}_{2} \mathrm{O}_{3} \\
(0.3 \sim 1.5)\end{array}$ & Sum \\
\hline 01-STS AOD & $0.97(2.00)$ & $61.24(59.80)$ & 29.50 & 7.50 & 1.20 & 0.51 & 100.51 \\
\hline 02-STS AOD & $1.70(3.50)$ & $60.41(57.90)$ & 28.50 & 8.50 & 1.50 & 0.35 & 100.25 \\
\hline 03-STS AOD & $2.29(4.70)$ & $61.58(58.20)$ & 25.40 & 5.07 & 2.33 & 1.45 & 97.15 \\
\hline 04-STS AOD & $2.60(5.35)$ & $61.52(57.68)$ & 26.50 & 6.50 & 1.45 & 1.75 & 99.23 \\
\hline 05-STS AOD & $3.28(6.74)$ & $62.44(57.60)$ & 24.90 & 6.60 & 1.23 & 1.25 & 98.32 \\
\hline 06-STS AOD & $3.55(7.30)$ & $61.44(56.20)$ & 28.20 & 6.98 & 0.85 & 0.75 & 100.28 \\
\hline 07-STS AOD & $3.89(8.00)$ & $63.35(57.60)$ & 26.30 & 7.14 & 1.05 & 0.50 & 100.59 \\
\hline 08-STS AOD & $4.50(9.24)$ & $62.42(55.78)$ & 25.30 & 4.78 & 1.24 & 1.43 & 97.77 \\
\hline 09-STS AOD & 4.94 (10.16) & $62.08(54.78)$ & 23.89 & 5.23 & 0.98 & 1.89 & 96.93 \\
\hline 10-STS AOD & $5.68(11.67)$ & $61.94(53.56)$ & 23.98 & 4.46 & 2.95 & 0.64 & 97.26 \\
\hline 11-STS AOD & $6.18(12.70)$ & $64.22(55.10)$ & 25.50 & 5.56 & 0.25 & 1.02 & 100.13 \\
\hline 12-STS AOD & $6.79(13.95)$ & $63.12(53.10)$ & 22.75 & 4.25 & 2.25 & 0.72 & 97.02 \\
\hline 13-STS AOD & $7.24(14.87)$ & $60.78(50.10)$ & 20.30 & 9.95 & 3.00 & 0.34 & 98.56 \\
\hline
\end{tabular}

(a)
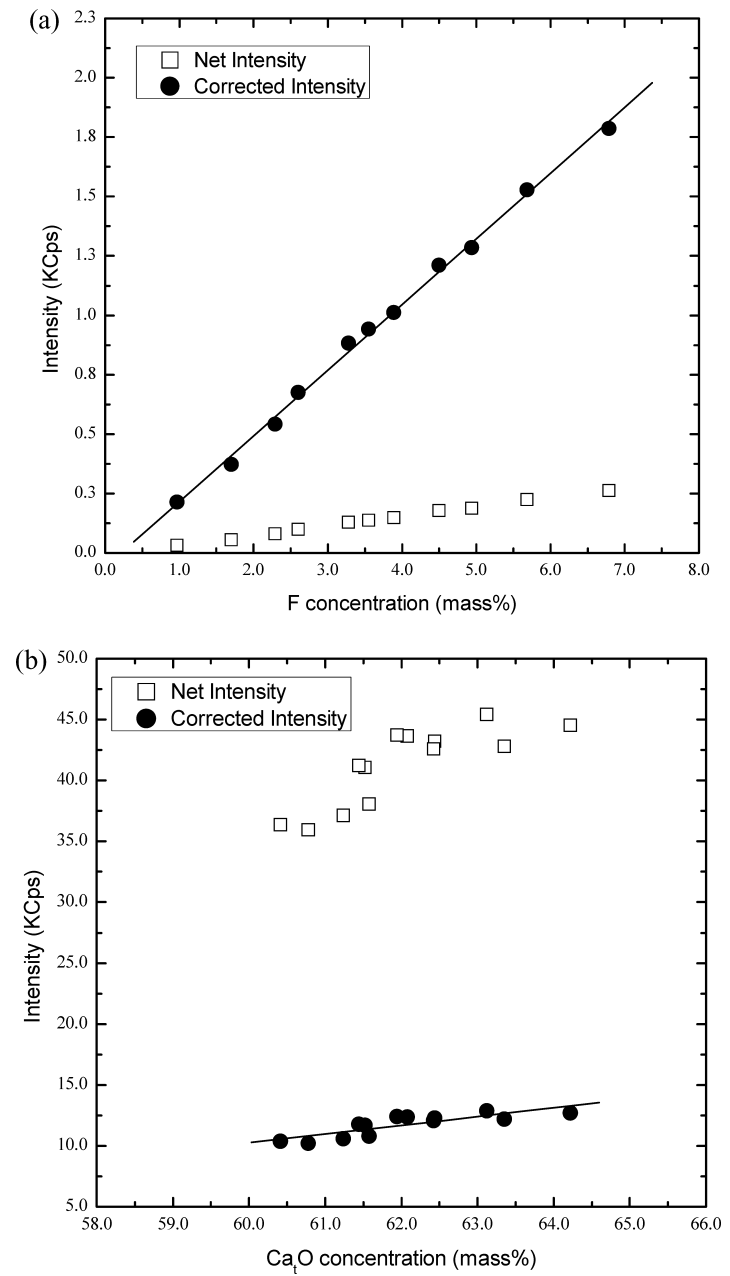

Fig. 4. XRF Calibration curves of fluorine (a) and total calcium oxide (b) with matrix effects and line overlap corrections.

\subsection{Construction of the Calibration Curves for STS AOD Slags and Evaluation of their Validity}

The 13 synthetic standards were prepared as fused glass discs by lithium borate mix fusion technique. The calibration curves of $\mathrm{F}$ and $\mathrm{Ca}_{\mathrm{t}} \mathrm{O}$ were presented in Fig. 4. Each calibration curve was obtained by applying matrix corrections with the help of variable alpha coefficient method and line overlap corrections. The calibration curves of other oxides $\left(\mathrm{SiO}_{2}, \mathrm{MgO}, \mathrm{Al}_{2} \mathrm{O}_{3}\right.$, and $\left.\mathrm{Cr}_{2} \mathrm{O}_{3}\right)$ present in STS AOD slags were represented in Fig. 5. Almost all of the calibration curves indicate good linear correlations between corrected X-ray intensity and concentrations of fluorine $(\mathrm{F})$ and other oxides for the investigated compositional range of each component. Therefore, it was believed that the prepared synthetic standards can be appropriately applied to XRF calibration for the chemical analysis of STS AOD slags.

In order to evaluate the validity of the XRF calibration curves, five repeated XRF measurements were made on one of the synthetic standards used for XRF calibration. As shown in Table 7, XRF analyses of the STS AOD slag components are quite precise since all the precision RSD values for each component show less than about $1 \%$. As an accuracy test, highly pure calcium fluoride (Sigma-Aldrich $99.5+$ mass $\%$ ) and an STS AOD Slag were measured in the form of fused glass disc and then evaluated according to the XRF calibration curves since any standard reference material containing a certified amount of calcium fluoride is not available. As shown in Table 8, the analysis results by $\mathrm{KMnO}_{4}$ titration and XRF measurement are comparable and acceptable considering that small portion of the samples vaporize during borate fusion process and that the ac- 

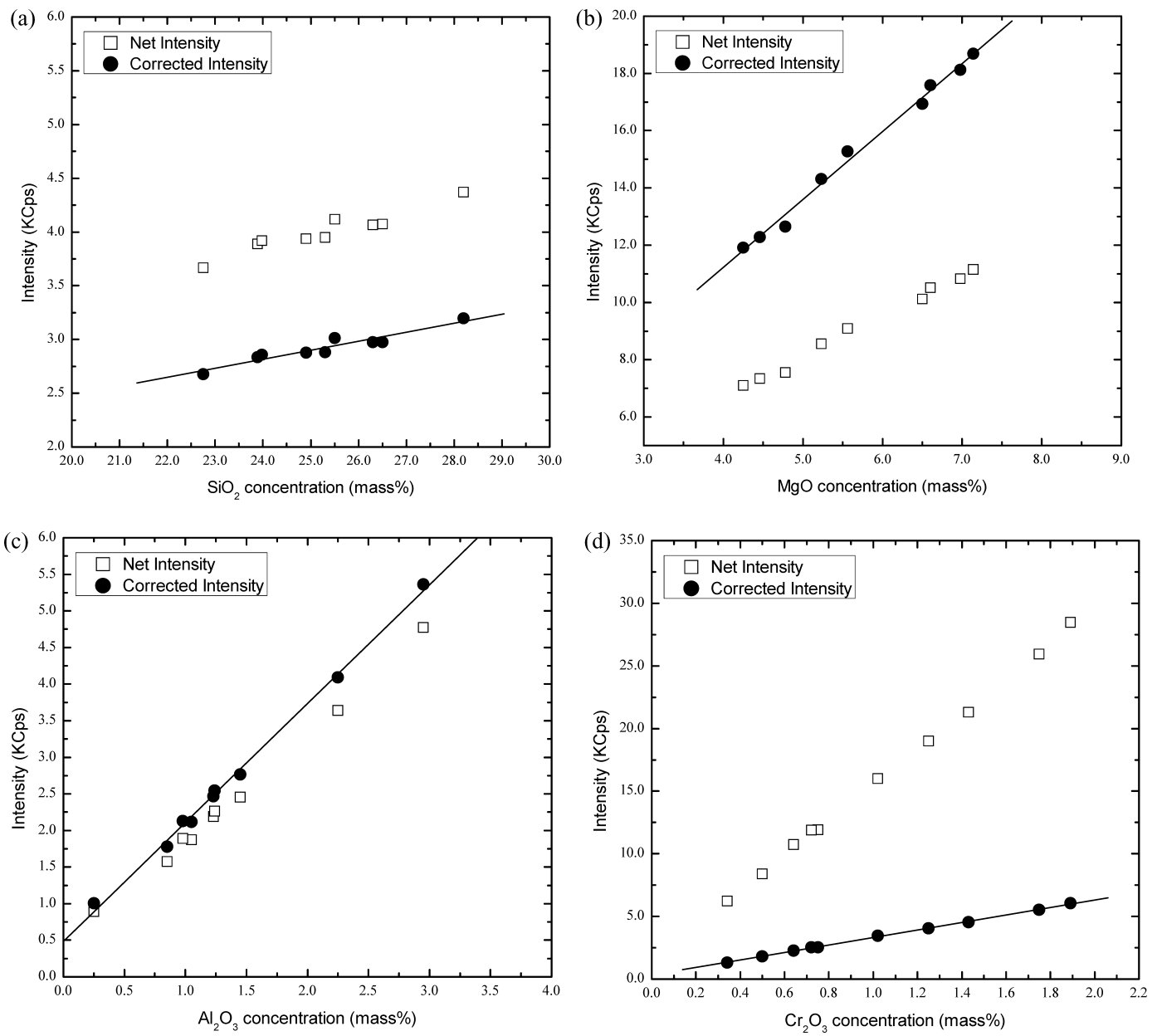

Fig. 5. XRF Calibration curves of silicon oxide (a), and magnesium oxide (b), aluminum oxide (c), and chromium oxide (d) with matrix and line overlap corrections.

Table 7. Precision tests for a reference sample (04-STS AOD). (Units: mass\%)

\begin{tabular}{ccccccc}
\hline Tests & $\mathbf{F}\left(\mathrm{CaF}_{2}\right)$ & $\mathrm{Ca}_{\mathbf{t}} \mathbf{O}(\mathrm{CaO})$ & $\mathrm{SiO}_{2}$ & $\mathrm{MgO}$ & $\mathrm{Al}_{2} \mathrm{O}_{3}$ & $\mathrm{Cr}_{2} \mathrm{O}_{3}$ \\
\hline Test1 & $2.598(5.34)$ & $62.02(58.2)$ & 26.07 & 6.42 & 1.41 & 1.72 \\
\hline Test2 & $2.602(5.35)$ & $61.98(58.1)$ & 26.06 & 6.42 & 1.42 & 1.72 \\
\hline Test3 & $2.611(5.37)$ & $61.98(58.1)$ & 26.19 & 6.40 & 1.41 & 1.72 \\
\hline Test4 & $2.636(5.42)$ & $61.94(58.0)$ & 26.10 & 6.41 & 1.41 & 1.72 \\
\hline Test5 & $2.675(5.50)$ & $61.97(58.0)$ & 25.88 & 6.40 & 1.40 & 1.71 \\
\hline Average & $\mathbf{2 . 6 2 5 ( 5 . 3 9 )}$ & $\mathbf{6 1 . 9 8 ( 5 8 . 1 )}$ & $\mathbf{2 6 . 0 6}$ & $\mathbf{6 . 4 1}$ & $\mathbf{1 . 4 1}$ & $\mathbf{1 . 7 2}$ \\
\hline Gravimetrically & $2.600(5.34)$ & $61.52(57.7)$ & 26.50 & 6.50 & 1.45 & 1.75 \\
calculated Conc. & & & & & & \\
\hline Standard deviation & $0.032(0.059)$ & $0.030(0.060)$ & 0.11 & 0.01 & 0.01 & 0.00 \\
\hline Precision RSD (\%) & $1.22 \%(1.09 \%)$ & $0.05 \%(0.10 \%)$ & $0.43 \%$ & $0.17 \%$ & $0.38 \%$ & $0.18 \%$ \\
\hline
\end{tabular}

tual concentration of calcium fluoride, 99.5 mass $\%$, is out of the composition range covered by the fluorine calibration curve in Fig. 4. Therefore, the XRF calibration curves using the synthetic standards can be utilized for the quantitative chemical analysis of fluorine (calcium fluoride) in STS AOD slags with acceptable precision and accuracy for the sake of quality control of stainless steelmaking processes.

\section{Conclusions}

Using 13 synthetic standards for STS AOD slags provides excellent calibration curves for XRF spectrometry. 
Table 8. Comparison of the analysis results of highly pure $\mathrm{CaF}_{2}$ chemical (Calcium fluoride) by wet chemical analysis and XRF measurement.

\begin{tabular}{ccc}
\hline & \multicolumn{2}{c}{ mass\% $\mathrm{CaF}_{2}$} \\
\cline { 2 - 3 } Samples & $\mathrm{KMnO}_{4}$ titration $^{5}$ & XRF analysis \\
\hline Calcium fluoride (99.5+ mass\%) & 98.7 & 96.1 \\
(SIGMA-ALDRICH) & & 7.62 \\
\hline STS AOD Slag & 7.73 & \\
\hline
\end{tabular}

From the research, the following conclusions were obtained.

(1) According to the phase analysis of an STS AOD slag and two kinds of reference materials (S8 Slag and S9 ESR Slag), the chemical analysis of fluorine could be variable depending on the phase of fluorine, and the fluorine in STS AOD slag was confirmed to exist in the form of $\mathrm{CaF}_{2}$.

(2) Although the $\mathrm{KMnO}_{4}$ titration and ion selective method were employed in order to analyze fluorine contained in STS AOD slags and two kinds of reference materials (S8 Slag and S9 ESR Slag), neither showed satisfactory precision and accuracy.

(3) It was confirmed that the borate fusion technique was superior to pressed pellet method in terms of the semiquantitative XRF analysis for STS AOD slags, which enabled to prepare 13 synthetic standards physically by mixing their constituents in the laboratory.

(4) The XRF calibration curves showed that the prepared synthetic standards are believed to be applied to analyze STS AOD slags with acceptable precision and accuracy by evaluating their validities.

\section{Acknowledgements}

Financial support from POSCO is gratefully appreciated. And author is greatly grateful to Mr. Young-Joo Do and Gyu-Hae Hwang for their assistance in the sample preparations and chemical analyses in this work.

\section{REFERENCES}

1) P. Kozakevitch: Rev. Metall., 51 (1954), 569.

2) K. C. Mills: Mold Operation for Quality and Productivity, ISS, Warrendale, PA, (1991), 85.

3) R. J. Fruehan: The Making, Shaping and Treating of Steel, Steelmaking and Refining Volume, 11th ed., AISE Steel Foundation, Pittsburgh, PA, (1998), 727.

4) T. Emi and Y. Iida: Trans. ISS, 11 (1984), 20.

5) S. Wakamatsu: Tetsu-to-Hagané, 46 (1959), 769.

6) T. Ishii and M. Ihida: Bunseki Kagaku, 22 (1973), 665.

7) V. E. Buhrke, R. Jenkins and D. K. Smith: A Practical Guide for the Preparation of Specimens for X-Ray Fluorescence and X-Ray Diffraction Analysis, John Wiley \& Sons, New York, (1998), 35.

8) The Swedish Steel Producers' Association: S8 Slag, Certified by the Swedish Institute for Metals Research, (1969)

9) The Swedish Steel Producers' Association: S9 ESR Slag, Certified by the Swedish Institute for Metals Research, (2000)

10) Fusion Methods Handbook, Automated Fusion Technology, Inc., Bayswater, Australia, (2001), 3

11) M. Shinmei, H. Uematsu, T. Maekawa and T. Yokogawa: Can. Metall. Q., 22 (1983), 53.

12) K. Schwerdfeger and K. Klein: Proc. 4th Int. Symp. on Electroslag Remelting Processes, ISIJ, Tokyo, (1973), 81.

13) R. Jenkins, R. W. Gould and D. Gedcke: Quantitative X-ray Spectrometry, Marcel Dekker, New York, (1995), 271; 344.

14) K. Shimizu, T. Suzuki, I. Jimbo and A. W. Cramb: Trans. ISS, 28 (2001), 87.

15) M. Loubser, C. Strydom and H. Potgieter: X-Ray Spectrom., 33 (2004), 212.

16) SPECTRAplus User's Manual, Vol. FQUANT, Version 1.6, BrukerAXS, GmbH, Karlsruhe, Germany, (2004), 78. 